\title{
Increased nicotinamide nucleotide transhydrogenase levels predispose to insulin hypersecretion in a mouse strain susceptible to diabetes
}

\author{
K. Aston-Mourney $\cdot$ N. Wong $\cdot$ M. Kebede $\cdot$ S. Zraika $•$ \\ L. Balmer • J. M. McMahon • B. C. Fam • J. Favaloro • \\ J. Proietto • G. Morahan • S. Andrikopoulos
}

Received: 15 May 2007 / Accepted: 17 July 2007 / Published online: 6 October 2007

(C) Springer-Verlag 2007

\begin{abstract}
Aims/hypothesis Insulin hypersecretion may be an independent predictor of progression to type 2 diabetes. Identifying genes affecting insulin hypersecretion are important in understanding disease progression. We have previously shown that diabetes-susceptible DBA/2 mice congenitally display high insulin secretion. We studied this model to map and identify the gene(s) responsible for this trait.

Methods Intravenous glucose tolerance tests followed by a genome-wide scan were performed on 171 (C57BL/6 $\times$ $\mathrm{DBA} / 2) \times \mathrm{C} 57 \mathrm{BL} / 6$ backcross mice.

Results A quantitative trait locus, designated hyperinsulin production-1 (Hip1), was mapped with a logarithm of odds score of 7.7 to a region on chromosome 13. Production of congenic mice confirmed that Hipl influenced the insulin hypersecretion trait. By studying appropriate recombinant inbred mouse strains, the Hip1 locus was further localised to a $2 \mathrm{Mb}$ interval, which contained only nine genes. Expression analysis showed that the only gene differentially expressed in islets isolated from the parental strains was Nnt, which encodes the mitochondrial proton pump,

G. Morahan and S. Andrikopoulos contributed equally to this study.

K. Aston-Mourney $\cdot$ N. Wong $\cdot$ M. Kebede $\cdot$ S. Zraika

J. M. McMahon • B. C. Fam · J. Favaloro · J. Proietto •

S. Andrikopoulos $(\bowtie)$

The University of Melbourne Department of Medicine (AH/NH),

Heidelberg Repatriation Hospital,

Heidelberg Heights,

Melbourne, Victoria 3081, Australia

e-mail: sof@unimelb.edu.au

L. Balmer · G. Morahan

Centre for Diabetes Research, Western Australian

Institute for Medical Research, and Centre for Medical Research,

University of Western Australia,

Crawley, Western Australia, Australia
\end{abstract}

nicotinamide nucleotide transhydrogenase (NNT). We also found in five mouse strains a positive correlation $\left(r^{2}=0.90\right.$, $p<0.01$ ) between NNT activity and first-phase insulin secretion, emphasising the importance of this enzyme in beta cell function. Furthermore, of these five strains, only those with high NNT activity are known to exhibit severe diabetes after becoming obese.

Conclusions/interpretation Insulin hypersecretion is associated with increased Nnt expression. We suggest that NNT must play an important role in beta cell function and that its effect on the high insulin secretory capacity of the DBA/2 mouse may predispose beta cells of these mice to failure.

Keywords Genetic predisposition · Insulin secretion . Intravenous glucose tolerance test - Islet beta cell function . Quantitative trait locus

\begin{tabular}{|c|c|}
\hline \multicolumn{2}{|c|}{ Abbreviations } \\
\hline B6 & C57BL/6 mouse \\
\hline $\mathrm{BC}$ & backcross \\
\hline D2 & $\mathrm{DBA} / 2$ mouse \\
\hline Hip1 & hyperinsulin production-1 \\
\hline IPGTT & intraperitoneal glucose tolerance test \\
\hline LOD & logarithm of odds \\
\hline NNT & nicotinamide nucleotide transhydrogenase \\
\hline QTL & quantitative trait locus \\
\hline
\end{tabular}

\section{Introduction}

Type 2 diabetes is a polygenic disease which is often revealed following exposure to detrimental environmental influences such as obesity and inactivity [1,2]. Despite much investigation, the genetic components still remain 
unknown, due to the complex and interactive nature of the genes involved [3, 4]. Many candidate genes have been identified [5-10]; however, they do not fully explain the mechanisms or the heritability of the disease. Quantitative trait locus (QTL) analysis has been applied to type 2 diabetes, and while many regions of the human genome have been implicated in studies of different susceptible populations [11-15], only a few genes underlying these QTLs have been identified [16, 17].

Islet beta cell dysfunction causing reduced insulin secretion is a main contributor to hyperglycaemia in diabetes. However, prior to the development of secretory dysfunction it has been shown that some participants with obesity and a family history of type 2 diabetes (who are therefore at an increased risk of developing the condition) paradoxically hypersecrete insulin. While this early insulin hypersecretion may be in part secondary to insulin resistance, studies in obese participants have shown that insulin hypersecretion can be more prevalent than insulin insensitivity [18]. The possibility that in some individuals hypersecretion may be a primary defect is supported by the following studies: (1) a variant in the sulfonylurea receptor gene resulting in elevated fasting and glucose-induced plasma insulin concentrations has been described in nondiabetic Mexican Americans, an ethnic group with a high incidence of type 2 diabetes [19]; (2) a large pedigree segregating a defect in the sulfonylurea receptor causing hyperinsulinaemia early in life displayed gestational or permanent diabetes despite normal insulin sensitivity [20]; (3) a mutation in the glucokinase gene was described in a family of hyperinsulinaemic-hypoglycaemic participants, one of whom at the age of 48 years developed diabetes requiring insulin [21]; and (4) fasting hyperinsulinaemia has been shown to predict the development of type 2 diabetes independently of insulin resistance, again suggesting that insulin hypersecretion is not only an adaptive response to insulin resistance but may be a primary defect [22]. These studies suggest a causal link, such that the capacity to hypersecrete insulin may enhance the progression to failure by causing beta cell exhaustion [23] when the beta cell is placed under stress.

The DBA/2 mouse is a model of diabetes susceptibility. When exposed to genetically induced obesity and insulin resistance [24], it displays pancreatic islet atrophy and beta cell degranulation, leading to insulinopenia, overt hyperglycaemia and premature death. In contrast, the same genetic mutation on the $\mathrm{C} 57 \mathrm{BL} / 6$ or $129 / \mathrm{J}$ strains, while also resulting in obesity, insulin resistance and islet hyperplasia, only caused mild, transient hyperglycaemia [24]. Furthermore, a high glucose environment can also impair function of islets from DBA/2 (but not C57BL/6) mice, and this defect was associated with oxidative stress $[25,26]$. In the normal 'non-stressed' state, we have shown that insulin secretion is exaggerated in DBA/2 mice when compared with other strains including C57BL/6 and 129T2 mice [27-29]. Furthermore, we determined this was not attributable to insulin resistance (as assessed by the insulin tolerance test) and was in fact intrinsic to the islet, as glucose-stimulated insulin secretion from cultured islets also showed an exaggerated response in the case of DBA/2 islets [27]. The aim of the present study therefore was to identify the gene(s) responsible for the difference(s) in insulin secretion in DBA/2 compared with $\mathrm{C} 57 \mathrm{BL} / 6$ mice in the normal state. Prior to the completion of this study, Toye et al. reported the existence of a five exon deletion in the mitochondrial enzyme nicotinamide nucleotide transhydrogenase (NNT) gene (Nnt) in the C57BL/6 mouse, and in their hands this was associated with lack of insulin secretion in response to glucose and impaired glucose tolerance compared with the $\mathrm{C} 3 \mathrm{H} / \mathrm{HeH}$ strain [30]. Since we found that the $N n t$ gene was responsible for $\mathrm{DBA} / 2$ hypersecretion, we also evaluated the effect of the five exon deletion on insulin secretion.

\section{Methods}

Animals DBA/2, C57BL/6, 129T2, FVB/N, (DBA/2 × $\mathrm{C} 57 \mathrm{BL} / 6) \mathrm{F} 1$ and BALB/c mice were purchased from The Walter and Eliza Hall Institute for Medical Research (Kew, VIC, Australia). Backcross (BC) mice were generated by breeding $\mathrm{F} 1$ male to $\mathrm{C} 57 \mathrm{BL} / 6$ female mice. BXD recombinant inbred strains were a kind gift from H. C. Hsu and J. Mountz of the University of Alabama [31]. All mice were fed a standard laboratory rodent chow (74\% carbohydrate, $20 \%$ protein and $6 \%$ fat by weight; Barastoc, Pakenham, VIC, Australia). Only male mice were used for experiments. All animal procedures were approved by the Royal Melbourne Hospital or the Austin and Repatriation Medical Centre Animal Research Ethics Committee.

Intravenous glucose tolerance tests The intravenous glucose tolerance test (IVGTT) was performed as previously described [27, 32]. A glucose bolus (1 g/kg) was infused into the carotid artery and $200 \mu$ l blood samples were collected at $0 \mathrm{~min}$ (before), and 2, 5, 10, 15 and $30 \mathrm{~min}$ afterwards. Blood was centrifuged and the plasma was removed and stored at $-20^{\circ} \mathrm{C}$ for measurement of glucose and insulin concentrations. Erythrocytes were resuspended in heparinised saline and reinfused to prevent anaemic shock and volume depletion.

Intraperitoneal glucose tolerance test The intraperitoneal glucose tolerance test (IPGTT) was performed as described above for the IVGTT, except that the glucose bolus $(2 \mathrm{~g} / \mathrm{kg})$ was injected into the peritoneal cavity and $200 \mu \mathrm{l}$ blood 
samples were collected at 0 min (before), and 15, 30, 60 and $120 \mathrm{~min}$ following the glucose bolus. Blood was centrifuged and the plasma was removed and stored at $-20^{\circ} \mathrm{C}$ for measurement of glucose concentration.

Determination of plasma glucose and insulin concentration Plasma glucose was determined using the Analox GM7 Micro-Stat glucose analyser (Helena Laboratories, Mount Waverley, VIC, Australia). The rat Linco Insulin Radioimmunoassay kit (Linco Research Immunoassay, St Charles, MO, USA) was used to assay plasma insulin concentrations as per the manufacturer's directions. Samples were counted in a gamma counter and concentration calculated using an automated data reduction procedure.

Genotyping DNA was extracted from mouse-tail tips via the salting-out method. PCR using ${ }^{32} \mathrm{P}$-labelled dATP was performed with microsatellite markers chosen on the basis of polymorphism markers (using the Massachusetts Institute of Technology [Mit] database) between DBA/2 and C57BL/6 (Research Genetics, Huntsville, AL, USA) as previously described $[33,34]$. PCR products were separated by PAGE and visualised by autoradiography.

Logarithm of odds analysis For the genome-wide scan, a $\chi^{2}$ test was carried out at each microsatellite marker in the hyperinsulinaemic BC progeny. Logarithm of odds (LOD) was calculated from the $\chi^{2}$ value as described by Kruglyak and Lander [35]. A LOD $>3.3$ was considered to indicate significant genome-wide linkage [35].

Islet isolation Islets were isolated as previously described $[36,37]$. Briefly, pancreases were digested by intraductal injection of collagenase $\mathrm{P}(0.5 \mathrm{mg} / \mathrm{ml}$ in RPMI medium with $100 \mathrm{U} / \mathrm{ml}$ penicillin, $100 \mu \mathrm{g} / \mathrm{ml}$ streptomycin and $11.1 \mathrm{mmol} / \mathrm{l}$ glucose). After incubation at $37^{\circ} \mathrm{C}$ for approximately $20 \mathrm{~min}$ the tissue was disrupted by hand shaking. Islets were purified using a Ficoll gradient with a $25 \%$ (wt/vol.) stock solution and 23, 20.5 and $11 \%$ dilutions. Ficoll was diluted in Hanks' balanced salt solution containing $4.2 \mathrm{mmol} / 1 \mathrm{NaHCO}_{3}$, $24 \mathrm{mmol} / 1 \mathrm{HEPES}, 100 \mathrm{U} / \mathrm{ml}$ penicillin and $100 \mu \mathrm{g} / \mathrm{ml}$ streptomycin. Islets were then hand picked under a stereoscopic microscope (Olympus, Tokyo, Japan) and transferred for overnight culture in RPMI medium with $10 \%$ (vol./vol.) heat-inactivated fetal calf serum, in a $37^{\circ} \mathrm{C}$ humidified atmosphere of $95 \% \mathrm{O}_{2} / 5 \% \mathrm{CO}_{2}$.

Insulin content Pancreases were homogenised in acidethanol, followed by a freeze-thaw cycle at $-20^{\circ} \mathrm{C}$ and sonication for $20 \mathrm{~min}$ on ice. The lysate was centrifuged at $10,000 \times g$ for $10 \mathrm{~min}$ and the supernatant fraction assayed for insulin. Protein concentration was measured by the Bio-Rad Protein Assay kit (Bio-Rad, Hercules, CA, USA).
Islet cDNA preparation Islets were hand picked and washed with $37^{\circ} \mathrm{C}$ PBS. Membranes were lysed and DNA was sheared by drawing islets in solution D $(4 \mathrm{~mol} / 1$ guanidinium thiocyanate, $25 \mathrm{mmol} / 1$ sodium citrate, $0.5 \%$ sarcosyl, $0.1 \mathrm{~mol} / \mathrm{l} \beta$-mercaptoethanol) through a 23 gauge needle. Sodium acetate and acid phenol were added before vortexing followed by chloroform-isoamyl alcohol isolation. The resulting upper aqueous phase was transferred to an equal volume of isopropanol and RNA was precipitated overnight at $-20^{\circ} \mathrm{C}$. The RNA was pelleted, washed with ethanol and resuspended in diethyl pyrocarbonate-treated water. Total RNA was then reverse transcribed using the Promega Reverse Transcription System kit (Promega Corporation, Madison, WI, USA) and any contaminating DNA removed by DNase treatment.

Real-time PCR analysis Specific primers for real-time PCR analysis were designed using Primer Express (version 1.0) software and synthesised by Geneworks Pty Ltd (Hindmarsh, SA, Australia). Real-time expression was determined using SYBR green PCR master mix (Applied Biosystems, Scoresby, VIC, Australia) with the Perkin-Elmer ABI Prism 7700 Sequence Detector and Sequence Detection Systems (version 1.9.1, Applied Biosystems) software. Insulin and $\beta$-actin were used as controls and all expression levels were normalised for cDNA concentration. Standard curves were incorporated to ensure all assays were measured in the linear detection range.

Hyperinsulin production-1 (Hipl) congenic strains Congenic mice were created by repeated backcrossing, from a $\mathrm{C} 57 \mathrm{BL} / 6 \times \mathrm{DBA} / 2 \mathrm{~F} 1$ mouse, while selecting for heterozygosity at the Hip1 locus using the genotyping method as above. The B6.D2-Hip1 ${ }^{d}$ mice were backcrossed to the C57BL/6 parental strain while the D2.B6-Hip $1^{b}$ mice were backcrossed to the DBA/2 parental strain for at least nine generations.

NNT enzyme assay Mitochondria were isolated from mouse pancreases using a modified version of the method described previously for rat pancreases [38]. The whole pancreas was homogenised in $1 \mathrm{ml}$ homogenisation medium (192 mmol/l mannitol, $58 \mathrm{mmol} / \mathrm{l}$ sucrose, $2 \mathrm{mmol} / 1$ TRIS-HCl [pH 7.4], $0.5 \mathrm{mmol} / 1 \mathrm{EDTA}, 0.5 \%$ bovine serum albumin [BSA]) and centrifuged at $700 \times \mathrm{g}$ for $7 \mathrm{~min}$ to pellet cell debris. The supernatant fraction was centrifuged at $8,000 \times g$ for $10 \mathrm{~min}$ to pellet the mitochondria, which were washed twice with $500 \mu \mathrm{l}$ homogenisation medium, and the pellet resuspended in $1 \mathrm{ml}$ homogenisation medium. The suspension was slowly homogenised for $30 \mathrm{~s}$, then centrifuged at $8,000 \times g$ for $10 \mathrm{~min}$. The resultant pellet was washed twice in medium not containing BSA (192 mmol/l mannitol, $58 \mathrm{mmol} / 1$ sucrose, $2 \mathrm{mmol} / 1$ TRIS- 

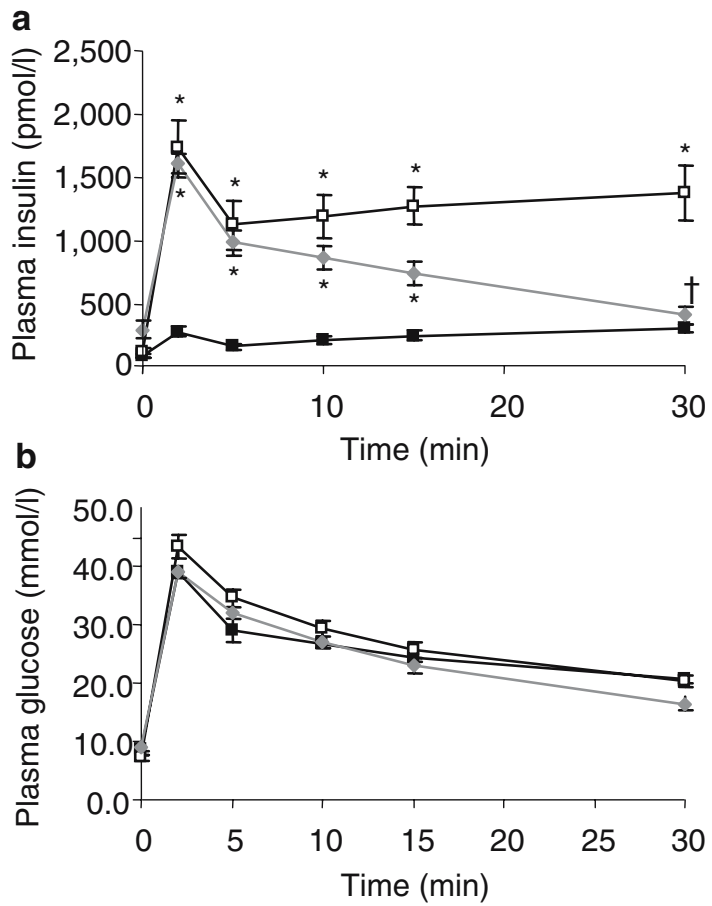

Fig. 1 a Plasma insulin concentrations during an IVGTT $(1 \mathrm{~g} / \mathrm{kg}$ glucose bolus) in 8-week-old DBA/2 (open squares), C57BL/6 (closed squares) and $\mathrm{C} 57 \mathrm{BL} / 6 \times \mathrm{DBA} / 2 \mathrm{~F} 1$ (diamonds) mice. Means $\pm \mathrm{SEM}$ $(n=10) .{ }^{*} p<0.05$ compared with $\mathrm{C} 57 \mathrm{BL} / 6, \dagger p<0.05$ compared with DBA $/ 2$. b Plasma glucose concentrations during the IVGTT $(1 \mathrm{~g} / \mathrm{kg}$ glucose bolus) in 8-week-old DBA/2 (open squares), C57BL/6 (closed squares) and $\mathrm{C} 57 \mathrm{BL} / 6 \times \mathrm{DBA} / 2 \mathrm{~F} 1$ (diamonds) mice. Means $\pm \mathrm{SEM}$ $(n=10)$

$\mathrm{HCl}$ [pH 7.4], $0.5 \mathrm{mmol} / \mathrm{l} \mathrm{EDTA})$ and resuspended in $50 \mu \mathrm{l}$ of the same medium.

The NNT enzyme assay was modified from the method described by Rydstrom [39] using the substrate analogue system. One millilitre of assay medium $(250 \mathrm{mmol} / \mathrm{l}$ sucrose, $50 \mathrm{mmol} / 1$ TRIS-acetate [pH 7.5], $0.33 \mathrm{mg}$ rotenone, $500 \mu \mathrm{mol} / 1 \mathrm{NADH}, 500 \mu \mathrm{mol} / 1$ acetylpyridine $\mathrm{NAD}^{+}$was incubated at $30^{\circ} \mathrm{C}$ for $3 \mathrm{~min}$. The absorbance at $375 \mathrm{~nm}$ was then recorded for 1-2 min until a steady state in absorbance was reached. Twenty microlitres of a mitochondrial preparation were then added to the cuvette in the spectrophotometer and the absorbance recorded for another $2 \mathrm{~min}$. The NNT reaction gradient was calculated using Beer's law from the period of greatest absorbance increase after the mitochondrial preparation had been added.

Statistical analysis Data are presented as means \pm SEM. The AUC (for glucose or insulin) was calculated using the trapezoidal rule. Statistical significance was determined using Student's $t$ test. A $p$ value $<0.05$ was considered statistically significant.

\section{Results}

C57BL/6 (B6) mice are extremely well characterised in terms of their physiology and genetics; they are commonly used as controls in many studies. The insulin secretion displayed by B6 mice (Fig. 1) was in the range that many other researchers have published (e.g. [40, 41]). In contrast, the DBA/2 mice secreted significantly more insulin in response to a glucose challenge (Fig. 1a). This effect was observed at all time-points and was not due either to differing glucose concentrations eliciting an appropriate insulin response (Fig. 1b) or to differences in pancreatic insulin content $(218 \pm 68$ vs $207 \pm 27 \mathrm{mg} / \mu \mathrm{g}$ protein, DBA $/ 2$ vs B6). This hypersecretion phenotype was observed at all ages from neonates (not shown) to 8 weeks (Fig. 1) and in DBA/2 mice as old as 40 weeks of age [27-29].

To determine the genetic basis of this difference in insulin secretion, $(\mathrm{C} 57 \mathrm{BL} / 6 \times \mathrm{DBA} / 2) \mathrm{F} 1$ mice were subjected to IVGTTs. The F1 mice also exhibited insulin hypersecretion
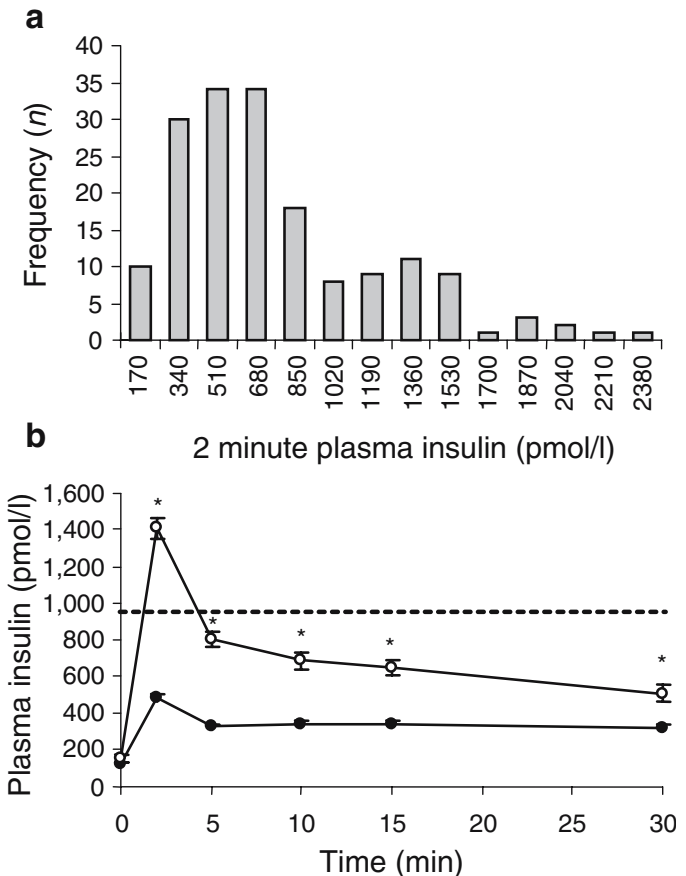

Fig. 2 a Histogram of the 2 min plasma insulin concentration following the IVGTT of all $171(\mathrm{C} 57 \mathrm{BL} / 6 \times \mathrm{DBA} / 2) \times \mathrm{C} 57 \mathrm{BL} / 6$ $\mathrm{BC}$ mice. From these data it was deduced that $950 \mathrm{pmol} / 1$ would be used to determine whether a $\mathrm{BC}$ mouse was a high (DBA/2-like) or low (C57BL/6-like) responder. b Plasma insulin concentrations during the IVGTT ( $1 \mathrm{~g} / \mathrm{kg}$ glucose bolus) in 8 -week-old $\mathrm{BC}$ mice. The animals were assigned based on their 2 min plasma insulin concentrations as either high responders ( $>950 \mathrm{pmol} / 1$, open circles) or low responders $(<950 \mathrm{pmol} / \mathrm{l}$, closed circles $)$ mice. The dashed line represents the $950 \mathrm{pmol} / 1$ plasma insulin concentration cut-off for the 2 min time-point. Means \pm SEM. ${ }^{*} p<0.05$ compared with low responders 
(Fig. 1a). These data suggested that the gene(s) controlling insulin hypersecretion in DBA/2 mice acted in a dominant fashion.

Next, $(\mathrm{C} 57 \mathrm{BL} / 6 \times \mathrm{DBA} / 2) \times \mathrm{C} 57 \mathrm{BL} / 6 \mathrm{BC}$ mice $(n=171)$ were generated and phenotyped using the IVGTT. From Fig. 1a, it is clear that the early-phase (i.e. $2 \mathrm{~min}$ ) insulin secretion following the i.v. glucose bolus was significantly different between the strains. Therefore, the insulin concentration at this time-point was used to rank the $\mathrm{BC}$ mice. Analysis of the $2 \mathrm{~min}$ insulin release in the $\mathrm{BC}$ mice showed that they appeared to fall into three populations that were each approximately normally distributed (Fig. 2a). The medium- and high-responding groups were classified as 'DBA/2-like' and the lower responder population 'B6-like', with the upper cut-off for this group at a plasma insulin concentration of $950 \mathrm{pmol} / \mathrm{l}$. Consequently, the high responder $\mathrm{BC}$ mice displayed higher plasma insulin concentrations at all time-points following the glucose bolus (Fig. 2b). Twenty-three per cent (39/171) of $\mathrm{BC}$ mice had a 2 min plasma insulin concentration $>950 \mathrm{pmol} / \mathrm{l}$. A phenotype controlled by a single gene would be expected to be seen in $50 \%$ of the BC mice, so the observation of only $23 \%$ of $\mathrm{BC}$ displaying hypersecretion suggests that more than one gene contributed to this trait.

A genome-wide scan of those $\mathrm{BC}$ mice exhibiting insulin hypersecretion identified a locus on the distal portion of chromosome 13 with highly significant linkage (LOD=7.7; Fig. 3). QTL analysis using all $171 \mathrm{BC}$ mice, including the low responders, placed this locus between D13Mit130 and D13Mit35, a distance of $17 \mathrm{Mb}$ (according to University of California Santa Cruz Assembly, May $2004)$ with a $90 \% \mathrm{CI}\left(p=2.6 \times 10^{-7}\right)$. The very significant linkage score prompted us to designate this locus for insulin hypersecretion in the DBA/2 mouse as Hip1.

BXD recombinant inbred mice [31] have mosaic chromosomes derived from the $\mathrm{DBA} / 2$ and $\mathrm{B} 6$ parental strains. BXD strains with recombinations on distal chromosome 13 were used to refine further the location of Hip1. While the BXD-28 strain showed insulin secretion comparable with $\mathrm{B} 6$ mice, the BXD-12 strain exhibited insulin hypersecretion, like the DBA/2 mouse, indicating this line inherited the DBA/2-derived alleles required for the phenotype (Fig. 4a).

The relevant genotypes of the BXD-12 and -28 strains are shown in Fig. 4b. Using the data from the genome-wide scan, and the physiological data from the recombinant inbred strains, it was determined that a $2 \mathrm{Mb}$ region at the end of chromosome 13 (between D13Mb115 and the telomere, indicated in Fig. 4b) harboured a gene capable of modifying insulin secretion.

This interval harbours seven annotated genes, two expressed sequence tags and one pseudogene. The expression of these genes in B6 and DBA/2 islets was examined using real-time PCR. The expression of nine of these genes was comparable between DBA/2 and B6. In addition, the expression levels of control genes for $\beta$-actin and insulin (Ins2) were determined and found to be comparable between B6 and DBA/2. Only one of the genes in this interval showed a significant difference between strains. This was Nnt, which encodes NNT, and its expression was more than fivefold higher in DBA/2 islets (Fig. 5).
Fig. 3 Genome-wide analysis of $(\mathrm{C} 57 \mathrm{BL} / 6 \times \mathrm{DBA} / 2) \times$ C57BL/6 BC mice showing significant linkage $(\mathrm{LOD}=7.7$, $p=2.6 \times 10^{-7}$ ) on chromosome 13 for the insulin hypersecretion trait

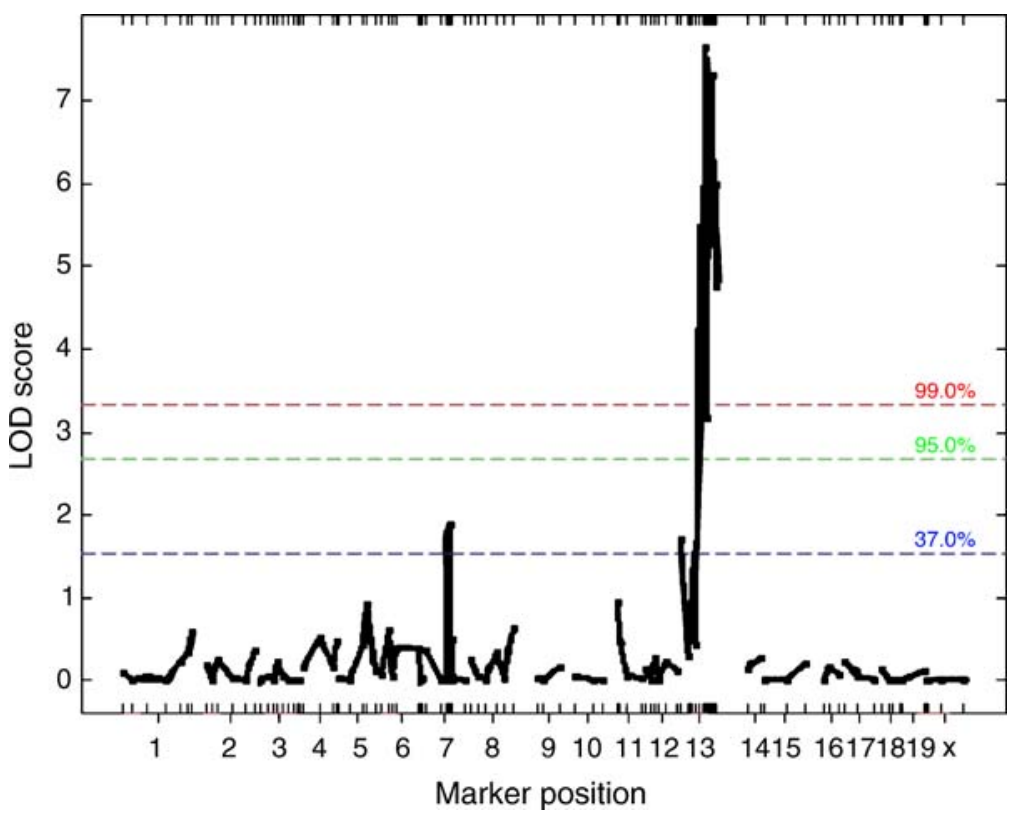


a

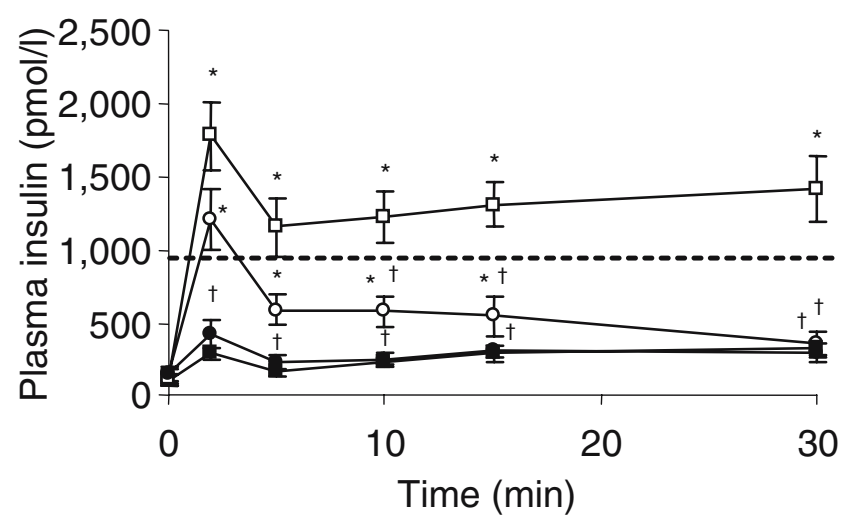

b

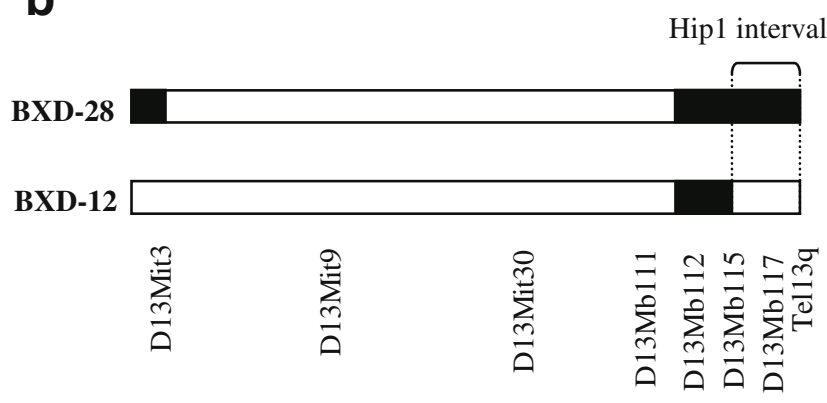

Fig. 4 a Plasma insulin concentrations during the IVGTT $(1 \mathrm{~g} / \mathrm{kg}$ glucose bolus) in 8-week-old DBA/2 (open squares), C57BL/6 (closed squares), BXD-12 (open circles) and BXD-28 (closed circles) mice. Means $\pm \operatorname{SEM}(n=8-10)$. Dashed line represents the $950 \mathrm{pmol} / 1 \mathrm{plasma}$ insulin concentration cut-off for the 2 min time-point. $* p<0.05$ compared with $\mathrm{C} 57 \mathrm{BL} / 6, \uparrow p<0.05$ compared with $\mathrm{DBA} / 2$. b The genotype of BXD-12 and BXD-28 recombinant inbred strains on chromosome 13. Markers are shown at approximate positions. Closed sections, C57BL/6 genotype; open sections, DBA/2 genotype. BXD-12 was hyperinsulinaemic and contained the DBA/2 alleles necessary for the phenotype. BXD-28 did not display hyperinsulinaemia and therefore does not have the alleles necessary. The region where BXD-12 has DBA/2 and BXD-28 has C57BL/6-derived DNA is the candidate gene location

To provide further support that Nnt influences glucosestimulated insulin secretion, we produced two reciprocal congenic strains. The first, B6.D2-Hip ${ }^{d}$, contained a very small segment of DBA/2 chromosome 13 on the B6 background. The DBA/2-derived congenic region in this strain contained only the fibroblast growth factor 10 ( Fgf-10, also known as Fgf10) and $N n t$ genes. Expression of $N n t$ was 2.5-fold increased in the B6.D2-Hip ${ }^{d}$ congenic line (Fig. 6a) and this was confirmed by a threefold increase in enzyme activity (Fig. 6b). Analyses of this congenic line by IVGTT and IPGTT showed that replacement of the B6 Nnt allele with the DBA/2 copy made no change from the B6 phenotype for either insulin secretion (Fig. 6c) or overall glucose tolerance (Fig. 6d). These data suggest that the truncated $\mathrm{Nnt}^{b}$ allele [30] is not responsible for the lower insulin secretion observed in B6 mice. Rather, the full-length $N n t$ allele is not even sufficient to increase its level of expression and activity to that seen in the DBA/2 strain (fivefold increase compared with $\mathrm{C} 57 \mathrm{BL} / 6$ ), suggesting the involvement of other gene(s) that regulate the expression of Nnt.

The reciprocal congenic strain, D2.B6-Hip $1^{b}$, has the B6 Hip $1^{b}$ allele on the DBA/2 background. Compared with the parental DBA/2 strain, these congenic mice did exhibit the expected reduction in Nnt expression (Fig. 6e) and NNT activity (Fig. 6f) levels, and these in turn resulted in both reduced first-phase insulin levels (Fig. 6g) and poorer glucose tolerance (Fig. 6h). Combined, these congenic data suggest that the presence of the DBA/2 allele of Hip1 is necessary but not sufficient for insulin hypersecretion and glucose tolerance.

To investigate further the impact of Nnt on insulin secretion, we determined pancreatic Nnt activity and compared this with first-phase insulin secretion in five strains of mice with different capacities for glucosemediated secretion. As mentioned earlier, it has recently been shown that a five exon deletion in $N n t$ was associated with a totally blunted insulin secretory response to glucose and impaired glucose tolerance in $\mathrm{B} 6$ compared with $\mathrm{C} 3 \mathrm{H} /$ $\mathrm{HeH}$ mice [30]. Of the five strains we tested, only B6 mice had the five exon deletion in Nnt (Fig. 7a). We also checked the status of Nnt in the two congenic lines we generated. As expected, the B6.D2-Hip $1^{d}$ congenic mice contained the full-length gene, while the D2.B6-Hip $1^{b}$ congenic mice had the truncated version of Nnt (Fig. 7b). As shown in Fig. 7c, a strong correlation $\left(r^{2}=0.901, p=0.01\right)$ was observed between NNT activity and first-phase insulin secretion, suggesting that Nnt is a powerful modulator of secretion.

It has been suggested [30] that the deletion in the B6 Nnt allele results in reduced secretion and was associated with poor glucose tolerance. We also found a significant correlation between reduced first-phase insulin release and glucose intolerance (Fig. 7d). However, this was independent of whether the deletion in Nnt was present (B6) or not

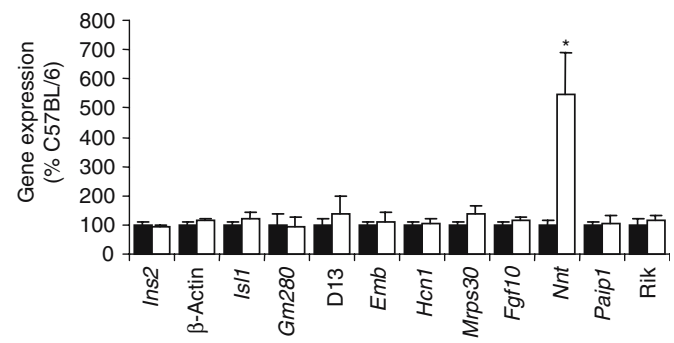

Fig. 5 Expression levels of the nine expressed genes and expressed sequence tags in the $2 \mathrm{Mb}$ Hip1 locus region as well as insulin and $\beta$-actin in $\mathrm{C} 57 \mathrm{BL} / 6$ (filled columns) and $\mathrm{DBA} / 2$ (open columns) islet mRNA measured by real-time PCR. Means \pm SEM $(n=4)$. ${ }^{*} p<0.005$ compared with C57BL/6 

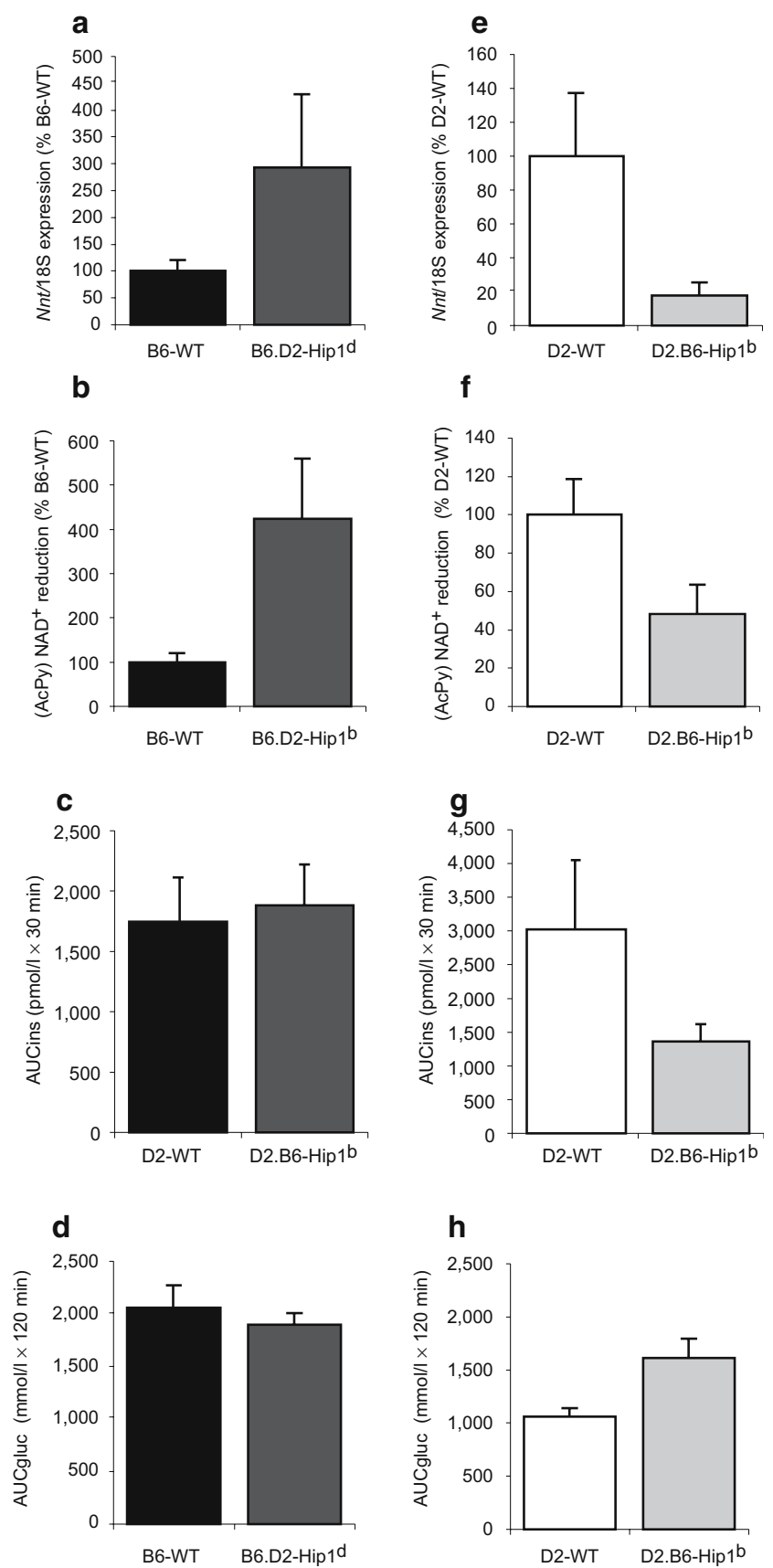

Fig. 6 a Nnt expression levels as assessed by real-time PCR. b NNT enzyme activity levels as assessed by (AcPy) $\mathrm{NAD}^{+}$reduction. c First-phase glucose-induced insulin secretion (AUC of insulin [AUCins]) and $\mathbf{d}$ glucose tolerance (AUC of glucose [AUCgluc]) in B6. D2-Hip ${ }^{d}$ mice compared with the wild-type $(W T)$ littermates. e Nnt expression levels as assessed by real-time PCR. f NNT enzyme activity levels. g First-phase glucose-induced insulin secretion and h glucose tolerance in D2.B6-Hip $1^{b}$ mice compared with the wildtype littermates. Means \pm SEM $(n=4-10)$. $A c P y$, acetylpyridine. ${ }^{*} p<0.05$ compared with respective wild-type control

(129T2) (Fig. 7a). Thus, the level of functional Nnt is the most important factor in first-phase insulin secretion and mice with low expression of full-length $N n t$ (e.g. 129T2) also have reduced insulin secretion.

\section{Discussion}

The DBA/2 mouse is a good animal model for studying susceptibility to beta cell dysfunction following exposure to a hyperglycaemic environment $[25,26]$ or genetically induced insulin resistance [24]. Our data indicate that DBA/2 mice hypersecrete insulin in response to glucose challenge, a trait that is strongly influenced by the Hip1 locus, which we mapped to a $2 \mathrm{Mb}$ region of chromosome 13. Analysis of the nine known genes in this region, and of only two in a further subcongenic region, indicated that Nnt, encoding NNT, was the probable causative gene underlying the Hip1 QTL and affecting the insulin hypersecretion phenotype in the DBA/2 mouse.

The Hip1 locus corresponds to a locus for glucose intolerance in the C57BL/6 compared with the $\mathrm{C} 3 \mathrm{H} / \mathrm{HeH}$ strain [30], for which these authors identified $N n t$ as the probable causative gene. The identification of the same gene in two independent studies, using different crosses of mouse strains and assessing different outcomes (insulin secretion and glucose tolerance), highlights the importance of Nnt in glucose homeostasis. Therefore, Nnt may be considered as a strong candidate gene in type 2 diabetes.

It is important to note that the phenotype of the $\mathrm{BC}$ mice presented in this article suggests the involvement of at least two genes in insulin hypersecretion in the DBA/2 mouse. Despite much effort investigating suggestive links on chromosomes 5, 6 and 7, the only significant linkage found was on chromosome 13, leading us to Nnt. Of interest are the results obtained from the B6.D2-Hip $1^{d}$ congenic mice, in which the truncated Nnt was replaced by the full-length version of this gene. If Nnt were the only gene contributing to the phenotype, these mice would be expected to increase the expression level of $N n t$ and insulin secretion to approximately the levels seen in the $\mathrm{DBA} / 2$ mouse. However, the B6.D2-Hip $1^{d}$ congenic mice showed only a two- to threefold increase in Nnt expression and activity levels, and these had no effect on insulin secretion. This was unexpected in light of the data presented by Freeman et al. showing that expression of the full-length $N n t$ (from $129 \mathrm{~S} 6 / \mathrm{SvEvTac}$ ) resulted in improvement in glucose tolerance and an increase in insulin secretion in the B6 mouse. However, these authors used a transgenic bacterial artificial chromosome containing Nnt and found an expression level of $N n t$ similar to that of $\mathrm{C} 3 \mathrm{H} / \mathrm{HeH}$ mice [42]. The combined data suggest that Nnt upregulation is required for insulin hypersecretion. Therefore, the second (and possibly other) gene(s) influencing insulin hypersecretion in the DBA/2 mouse may do so at least in part by affecting the expression of Nnt. There have been many genome-wide scans performed in humans for type 2 diabetes susceptibility loci, but to date none has shown significant linkage to the chromosome region containing Nnt (5p13.1-cen). This 


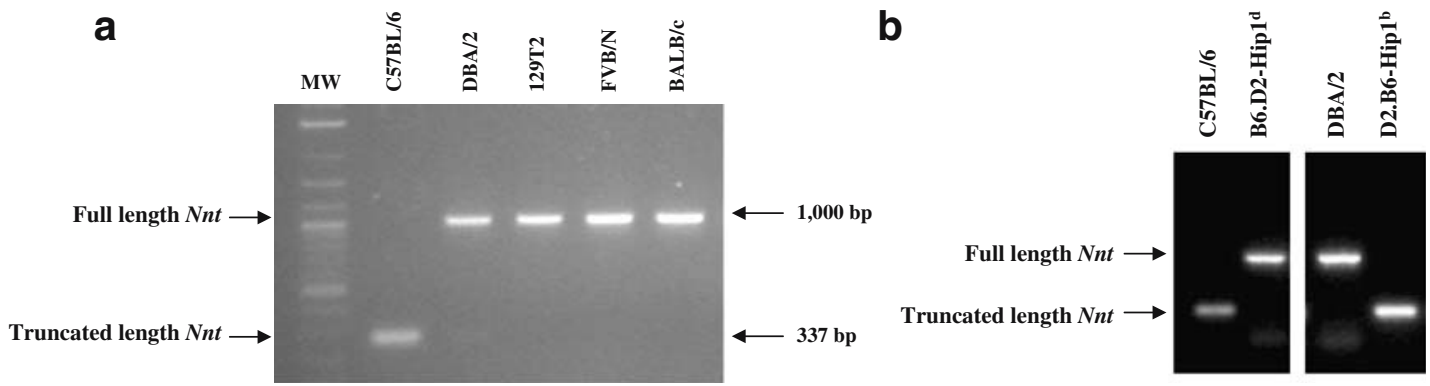

C

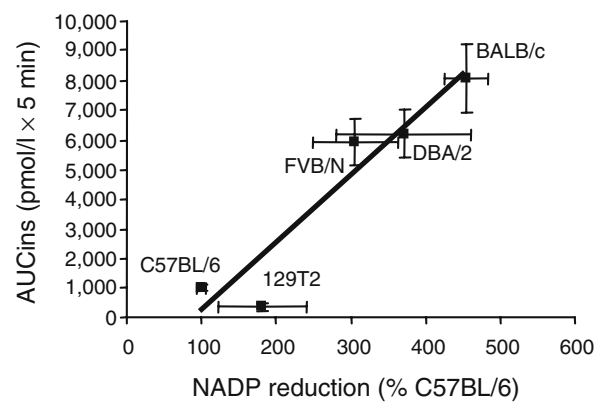

Fig. 7 a Agarose gel of a standard PCR performed between exons 7 and 13 of $N n t$ on C57BL/6, DBA/2, 129T2, FVB/N and BALB/c cDNA. The bands represent the full-length $N n t$ transcripts and the truncated transcript with the five exon deletion. $M M$, molecular mass markers. b Agarose gel of a standard PCR performed between exons 7 and 13 of Nnt on C57BL/6, B6.D2-Hip $1^{d}$ congenic, DBA/2 and D2.B6-Hip1 ${ }^{b}$ congenic mouse cDNA. The bands represent the full-length $N n t$ transcripts and the truncated transcript with the five exon deletion. c Correlation

may indicate that Nnt does not play an important role in human type 2 diabetes. However, as the current study indicates the epistatic role of another gene in influencing the expression of Nnt, it may in fact be that this second gene plays a more significant role in conferring either or both insulin hypersecretion and diabetes development. Therefore, identifying this second gene in the DBA/2 mouse model will allow researchers to test the role of the human orthologues of these genes in human diabetes. It is important to note that when we replaced the functional D2Nnt allele with the five exon-deleted variant in the D2.B6Hip $1^{b}$ congenic strain, we did find a decrease in secretion, supporting the important role of this gene in insulin release.

NNT catalyses a direct transfer of hydride ions between $\operatorname{NAD}(\mathrm{H})$ and $\mathrm{NADP}(\mathrm{H})$ in a reaction that is coupled to proton translocation across the mitochondrial inner membrane [43]. Additionally, since Nnt is involved in $\operatorname{NADP}(\mathrm{H})$ production, and one NADPH can be converted to three ATPs, it has the potential to result in increased ATP generation when its level is upregulated. As mitochondrial function and energy production within the islet beta cells is imperative for glucose-mediated insulin production and secretion, a change in Nnt function has the potential to alter the rate and amount of insulin released. An increase in ATP d

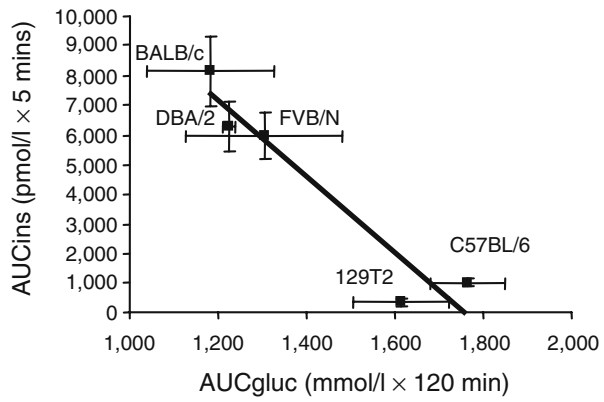

between first-phase insulin secretion (AUC of insulin [AUCins]) as measured by the IVGTT and NNT activity as assessed by the reduction of NADP in C57BL/6, DBA/2, 129T2, FVB/N and BALB/c mice. $R=0.901, p=0.01$. Values are means \pm SEM. $\mathbf{d}$ Correlation between firstphase insulin secretion (AUC of insulin $[A U C i n s]$ ) as measured by the IVGTT, and AUC of glucose (AUCgluc) as measured by the IPGTT, in C57BL/6, DBA/2, 129T2, FVB/N and BALB/c mice. $r=0.908, p=0.01$. Values are means \pm SEM

levels is critical in the early, first-phase, glucose-mediated insulin secretion, closing the $\mathrm{K}_{\text {ATP }}$ potassium channels and depolarising the plasma membrane as well as providing the energy for trafficking, docking and fusion of the secretory granules. We have previously shown that glucose metabolism [27] and ATP levels [37] are increased in DBA/2 islets, providing support for $N n t$ being the causative gene in insulin hypersecretion in this strain.

It has previously been shown that $\mathrm{FVB} / \mathrm{N}$ and $\mathrm{BALB} / \mathrm{c}$ are highly susceptible to developing diabetes when put under physiological stress [44, 45]. It was significant that, like DBA/2, both FVB/N and BALB/c mice displayed both high Nnt activity and high insulin secretion capacity. Why could an increase in insulin secretory capacity lead to beta cell failure? An increase in glucose-induced insulin secretion requires an increase in glucose utilisation and metabolism and thereby mitochondrial metabolism. Normal functioning of the mitochondria produces free radicals, which react with oxygen and produce reactive oxygen species. These can cause a reduction in mitochondrial operations, decreased ATP synthesis, dysregulated calcium homeostasis and ultimately cell death. As mentioned earlier, we have previously shown that the DBA/2 islets do have an increase in glucose utilisation and ATP content when 
hypersecreting insulin [27, 37]. Furthermore when the islets were placed under conditions of stress resulting in beta cell failure, a decrease in ATP content and an increase in oxidative stress was observed [26]. If $\mathrm{Nnt}$ is the cause of insulin hypersecretion, it is possible that, when the animal is placed under insulin-resistant conditions such as severe obesity, overexpression resulting in increased mitochondrial metabolism is more harmful to the islet beta cell than underexpression.

In summary, we have shown the genetic basis of hyperinsulinaemia in a mouse model of type 2 diabetes to be under the control of at least two dominantly acting genes. The major gene effect was mediated by a strong QTL associated with glucose-mediated insulin hypersecretion mapping on chromosome 13 and it is probable that the gene responsible for this QTL is Nnt, which encodes the mitochondrial enzyme Nnt. Identification of genes involved in hyperinsulinaemia may lead to identification of individuals at risk of developing type 2 diabetes, which may improve the ability to initiate early treatment in order to prevent or delay disease onset.

Acknowledgements We thank R. Citroen, J. Davis, A. Blair, J. McKie and P. Brazzoduro for excellent assistance with this project. This study was supported by grants from the National Health and Medical Research Council (NHMRC) of Australia (numbers: 114169, 208945), the Diabetes Research Foundation (WA, Australia) and a summer studentship from the Juvenile Diabetes Research Foundation of Australia. S. Andrikopoulos was supported by a Career Development Award from the NHMRC and G. Morahan is a Senior Research Fellow of the NHMRC.

Duality of interest The authors declare that there is no duality of interest associated with this manuscript.

\section{References}

1. Zimmet P, Taylor R, Ram P et al (1983) Prevalence of diabetes and impaired glucose tolerance in the biracial (Melanesian and Indian) population of Fiji: a rural-urban comparison. Am J Epidemiol 118:673-688

2. Barnett AH, Eff C, Leslie RD, Pyke DA (1981) Diabetes in identical twins. A study of 200 pairs. Diabetologia 20:87-93

3. Proietto J, Andrikopoulos S, Rosella G, Thorburn A (1995) Understanding the pathogenesis of type 2 diabetes: can we get off the metabolic merry-go-rounds? Aust N Z J Med 25:870-875

4. Kaku K, Fiedorek FT Jr, Province M, Permutt MA (1988) Genetic analysis of glucose tolerance in inbred mouse strains. Evidence for polygenic control. Diabetes 37:707-713

5. Jowett JB, Elliott KS, Curran JE et al (2004) Genetic variation in BEACON influences quantitative variation in metabolic syndrome-related phenotypes. Diabetes 53:2467-2472

6. Awata T, Neda T, lizuka H et al (2004) Endothelial nitric oxide synthase gene is associated with diabetic macular edema in type 2 diabetes. Diabetes Care 27:2184-2190

7. Yoshioka K, Yoshida T, Umekawa T et al (2004) Adiponectin gene polymorphism (G276T) is not associated with incipient diabetic nephropathy in Japanese type 2 diabetic patients. Metabolism 53:1223-1226

8. Wang H, Zhang H, Jia Y et al (2004) Adiponectin receptor 1 gene (ADIPOR1) as a candidate for type 2 diabetes and insulin resistance. Diabetes 53:2132-2136

9. Elbein SC, Karim MA (2004) Does the aspartic acid to asparagine substitution at position 76 in the pancreas duodenum homeobox gene (PDX1) cause late-onset type 2 diabetes? Diabetes Care 27:1968-1973

10. Johansen A, Nielsen EM, Andersen G et al (2004) Large-scale studies of the functional $\mathrm{K}$ variant of the butyrylcholinesterase gene in relation to type 2 diabetes and insulin secretion. Diabetologia 47:1437-1441

11. Li WD, Dong C, Li D, Garrigan C, Price RA (2004) A quantitative trait locus influencing fasting plasma glucose in chromosome region 18q22-23. Diabetes 53:2487-2491

12. Gu HF, Efendic S, Nordman S et al (2004) Quantitative trait loci near the insulin-degrading enzyme (IDE) gene contribute to variation in plasma insulin levels. Diabetes 53:2137-2142

13. Vitt U, Gietzen D, Stevens K et al (2004) Identification of candidate disease genes by EST alignments, synteny, and expression and verification of Ensembl genes on rat chromosome 1q43-54. Genome Res 14:640-650

14. McQueen MB, Bertram L, Rimm EB, Blacker D, Santangelo SL (2003) A QTL genome scan of the metabolic syndrome and its component traits. BMC Genet 4(Suppl 1):S96

15. Almind K, Kulkarni RN, Lannon SM, Kahn CR (2003) Identification of interactive loci linked to insulin and leptin in mice with genetic insulin resistance. Diabetes 52:1535-1543

16. Malecki MT, Klupa T, Wanic K, Cyganek K, Frey J, Sieradzki J (2002) Vitamin D binding protein gene and genetic susceptibility to type 2 diabetes mellitus in a Polish population. Diabetes Res Clin Pract 57:99-104

17. Hanis CL, Boerwinkle E, Chakraborty R et al (1996) A genomewide search for human non-insulin-dependent (type 2) diabetes genes reveals a major susceptibility locus on chromosome 2. Nat Genet 13:161-166

18. Ferrannini E, Natali A, Bell P, Cavallo-Perin P, Lalic N, Mingrone G (1997) Insulin resistance and hypersecretion in obesity. J Clin Invest 100:1166-1173

19. Goksel DL, Fischbach K, Duggirala R et al (1998) Variant in sulfonylurea receptor-1 gene is associated with high insulin concentrations in non-diabetic Mexican Americans: SUR-1 gene variants and hyperinsulinemia. Hum Genet 103:280-285

20. Huopio H, Reimann F, Ashfield R et al (2000) Dominantly inherited hyperinsulinism caused by a mutation in the sulfonylurea receptor type 1. J Clin Invest 106:897-906

21. Glaser B, Kesavan P, Heyman M et al (1998) Familial hyperinsulinism caused by an activating glucokinase mutation. N Engl J Med 338:226-230

22. Weyer C, Hanson RL, Tataranni PA, Bogardus C, Pratley RE (2000) A high fasting plasma insulin concentration predicts type 2 diabetes independent of insulin resistance. Evidence for a pathogenic role of relative hyperinsulinemia. Diabetes 49: 2094-2101

23. Sako Y, Grill VE (1990) Coupling of beta-cell desensitization by hyperglycemia to excessive stimulation and circulating insulin in glucose-infused rats. Diabetes 39:1580-1583

24. Leiter EH, Coleman DL, Hummel KP (1981) The influence of genetic background on the expression of mutations at the diabetes locus in the mouse. III. Effect of H-2 haplotype and sex. Diabetes 30:1029-1034

25. Kooptiwut S, Kebede M, Zraika S et al (2005) High glucoseinduced impairment in insulin secretion is associated with reduction in islet glucokinase in a mouse model of susceptibility to islet dysfunction. J Mol Endocrinol 35:39-48 
26. Zraika S, Aston-Mourney K, Laybutt DR et al (2006) The influence of genetic background on the induction of oxidative stress and impaired insulin secretion in mouse islets. Diabetologia 49:1254-1263

27. Kooptiwut S, Zraika S, Thorburn AW et al (2002) Comparison of insulin secretory function in two mouse models with different susceptibility to beta-cell failure. Endocrinology 143:2085-2092

28. Bock T, Pakkenberg B, Buschard K (2005) Genetic background determines the size and structure of the endocrine pancreas. Diabetes 54:133-137

29. Andrikopoulos S, Massa CM, Aston-Mourney K et al (2005) Differential effect of inbred mouse strain (C57BL/6, DBA/2, 129T2) on insulin secretory function in response to a high fat diet. J Endocrinol 187:45-53

30. Toye AA, Lippiat JD, Proks $P$ et al (2005) A genetic and physiological study of impaired glucose homeostasis control in C57BL/6J mice. Diabetologia 48:675-686

31. Hsu HC, Zhang HG, Li L et al (2003) Age-related thymic involution in $\mathrm{C} 57 \mathrm{BL} / 6 \mathrm{~J} \times \mathrm{DBA} / 2 \mathrm{~J}$ recombinant-inbred mice maps to mouse chromosomes 9 and 10 . Genes Immun 4:402-410

32. Veroni MC, Proietto J, Larkins RG (1991) Evolution of insulin resistance in New Zealand obese mice. Diabetes 40:1480-1487

33. Dietrich W, Katz H, Lincoln SE et al (1992) A genetic map of the mouse suitable for typing intraspecific crosses. Genetics 131:423-447

34. Morahan G, Huang D, Wu M et al (2002) Association of IL12B promoter polymorphism with severity of atopic and non-atopic asthma in children. Lancet 360:455-459

35. Kruglyak L, Lander ES (1996) Limits on fine mapping of complex traits. Am J Hum Genet 58:1092-1093

36. Zraika S, Dunlop M, Proietto J, Andrikopoulos S (2002) The hexosamine biosynthesis pathway regulates insulin secretion via protein glycosylation in mouse islets. Arch Biochem Biophys 405: 275-279
37. Zraika S, Dunlop ME, Proietto J, Andrikopoulos S (2004) Elevated SNAP-25 is associated with fatty acid-induced impairment of mouse islet function. Biochem Biophys Res Commun 317:472-477

38. Hodarnau A, Dancea S, Barzu O (1973) Isolation of highly purified mitochondria from rat pancreas. J Cell Biol 59:222-227

39. Rydstrom J (1979) Assay of nicotinamide nucleotide transhydrogenases in mammalian, bacterial, and reconstituted systems. Methods Enzymol 55:261-275

40. Goren HJ, Kulkarni RN, Kahn CR (2004) Glucose homeostasis and tissue transcript content of insulin signaling intermediates in four inbred strains of mice: C57BL/6, C57BLKS/6, DBA/2, and 129X1. Endocrinology 145:3307-3323

41. Fex M, Nitert MD, Wierup N, Sundler F, Ling C, Mulder H (2007) Enhanced mitochondrial metabolism may account for the adaptation to insulin resistance in islets from $\mathrm{C} 57 \mathrm{BL} / 6 \mathrm{~J}$ mice fed a high-fat diet. Diabetologia 50:74-83

42. Freeman HC, Hugill A, Dear NT, Ashcroft FM, Cox RD (2006) Deletion of nicotinamide nucleotide transhydrogenase: a new quantitive trait locus accounting for glucose intolerance in C57BL/6J mice. Diabetes 55:2153-2156

43. Olausson T, Fjellstrom O, Meuller J, Rydstrom J (1995) Molecular biology of nicotinamide nucleotide transhydrogenase - a unique proton pump. Biochim Biophys Acta 1231:1-19

44. Haluzik M, Colombo C, Gavrilova O et al (2004) Genetic background $(\mathrm{C} 57 \mathrm{BL} / 6 \mathrm{~J}$ versus $\mathrm{FVB} / \mathrm{N})$ strongly influences the severity of diabetes and insulin resistance in ob/ob mice. Endocrinology 145: 3258-3264

45. Qiu J, Ogus S, Mounzih K, Ewart-Toland A, Chehab FF (2001) Leptin-deficient mice backcrossed to the BALB/cJ genetic background have reduced adiposity, enhanced fertility, normal body temperature, and severe diabetes. Endocrinology 142:34213425 